\title{
Development and characterization of 60 microsatellite markers in the abalone Haliotis diversicolor
}

\author{
Y. Wang, F. Wang, Y.H. Shi, Z.F. Gu, A.M. Wang
}

Key Laboratory of Tropical Biological Resources of Ministry of Education, Hainan Provincial Key Laboratory of Tropical Hydrobiology and Biotechnology, National Class Marine Biology Experiment Teaching Demonstration Center, Ocean College, Hainan University, Haikou, Hainan, China

Corresponding author: A.M. Wang / Y. Wang

E-mail: aimwang@163.com / wy2005@163.com

Genet. Mol. Res. 10 (2): 860-866 (2011)

Received November 29, 2010

Accepted February 15, 2011

Published May 9, 2011

DOI 10.4238/vol10-2gmr1182

\begin{abstract}
The abalone, Haliotis diversicolor, is one of the most important mariculture species in southern China. We developed 60 new polymorphic microsatellite markers for $H$. diversicolor and characterized them in 30 individuals from a cultured population in Sanya, China. All 60 markers were found to be polymorphic. The number of alleles ranged from two to nine per locus, with an average of 4.12/locus. The expected and observed heterozygosities ranged from 0.10 to 0.88 and from 0.07 to 0.87 , respectively. Forty-four loci were in Hardy-Weinberg equilibrium. These 44 microsatellite markers should be useful for genome mapping and population genetic studies.
\end{abstract}

Key words: Abalone; Microsatellite; Aquaculture; Haliotis diversicolor 


\section{INTRODUCTION}

Haliotis diversicolor, also called small abalone, is distributed throughout the coastal regions of southern China, Vietnam, Korea, and Japan, and is one of the most important commercial mariculture species (Rouvay, 2007). Selective breeding programs for economically important traits, such as disease-resistance and growth rate, have already been initiated (Ke et al., 2000; Shi et al., 2007). They will be greatly enhanced by identifying genetic markers associated with these traits. Genetic markers will facilitate pedigree reconstructions, the development of linkage maps, the identification of quantitative trait loci, and marker-assisted selection within these programs. Genetic markers could also be useful to study natural population structures and dispersal patterns.

Microsatellite markers are the markers of choice for many genetic studies (Schlotterer, 2004). To date, only 22 polymorphic microsatellite markers are available for $H$. diversicolor (Ren et al., 2008; Zhan et al., 2009). In this study, we report the development and characterization of 60 new microsatellite markers for $H$. diversicolor.

\section{MATERIAL AND METHODS}

\section{Samples and DNA extraction}

Thirty abalone samples were randomly collected from a cultured population in 2007 at Sanya Hongtang Abalone, Ltd., Hainan, China. The cultured population containing 50,000 individuals was produced by random mating.

DNA was extracted from the fresh gastropod muscles using the Cell/Tissue Genomic DNA Extraction kit (TianGen, Beijing, China).

\section{Microsatellite-enriched library construction and sequencing}

An enriched microsatellite DNA library was constructed using a selective hybridization and magnetic bead enrichment method (Wang et al., 2009), modified from Carleton et al. (2002). In brief, genomic DNA was digested using MboI (TaKaRa, Dalian, China). Fragments sized 300$1000 \mathrm{bp}$ were purified from agarose gels using the Gel DNA Extraction kit (TianGen). Following ligation of the fragments to double-stranded $\mathrm{MboI}$-adapters, the DNA-library was enriched for microsatellite-containing sequences by hybridization with biotin-labeled (CA) ${ }_{12},(\mathrm{GA})_{12},(\mathrm{ACA})_{8}$, $(\mathrm{AGA})_{8},(\mathrm{GACA})_{6}$, and (GATA) ${ }_{6}$ probes (mixed in advance at a ratio of $\left.3: 1: 1: 1: 2: 2\right)$. Hybridized DNA fragments were captured using Streptavidin MagneSphere ${ }^{\circledR}$ Paramagnetic Particles (Promega, USA). The microsatellite repeat-enriched elute was amplified by the polymerase chain reaction (PCR) using one strand of the adapter. The amplification products were purified with an Ultrafree column (Pall, USA), and cloned using the T-Easy system (Promega). Clones containing potential microsatellite loci were selected and sequenced on ABI 3730xl DNA analyzers at Sangon Biological Engineering Technology \& Services Co., Ltd. (Shanghai, China).

\section{Primer design and genotyping}

After removing vector and adaptor sequences, DNA sequences were aligned with each other and with $22 \mathrm{H}$. diversicolor microsatellite sequences from GenBank (accessed October 
11, 2010) to check for duplications, using Vector NTI Advance 11.0.0 (http://www.invitrogen. com). The MISA software (http://pgrc.ipk-gatersleben.de/misa/) was used to identify sequences containing at least six di-, five tri-, five tetra-, four penta-, and three hexa-, hepta- and octanucleotide repeats. PCR primers were designed from unique flanking sequences using Primer 3 (http://biotools.umassmed.edu/bioapps/primer3_www.cgi).

PCR was conducted in a final volume of $15 \mu \mathrm{L}$ and contained $\sim 30 \mathrm{ng}$ template DNA, $1 \mathrm{X}$ reaction buffer [20 mM Tris- $\mathrm{HCl}, \mathrm{pH} 8.4,20 \mathrm{mM} \mathrm{KCl}$ and $10 \mathrm{mM}\left(\mathrm{NH}_{4}\right)_{2} \mathrm{SO}_{4}$; TianGen], $1.5-2.0 \mathrm{mM} \mathrm{MgCl}, 0.2 \mathrm{mM}$ of each dNTP, 1.0 pmol of each primer pair, $0.4 \mathrm{U}$ Taq polymerase. PCR was performed in an Eppendorf Master Cycler Gradient (Germany) with the following steps: $94^{\circ} \mathrm{C}$ for $4 \mathrm{~min}$ followed by 38 cycles of $94^{\circ} \mathrm{C}$ for $30 \mathrm{~s}$, annealing (temperatures indicated in Table 1) for $30 \mathrm{~s}$ and $45 \mathrm{~s}$ at $72^{\circ} \mathrm{C}$, followed by a final extension at $72^{\circ} \mathrm{C}$ for $5 \mathrm{~min}$. Products were separated on $12 \%$ polyacrylamide gels and visualized with silver staining. Sizes of alleles were scored by reference to a 50-bp standard base pair ladder (TianGen).

\section{Statistical analysis}

GENEPOP on the web (http://genepop.curtin.edu.au/) was used to test for deviations from Hardy-Weinberg equilibrium (HWE) for each locus as well as for linkage disequilibrium (LD) between all pairs of loci (exact tests, 1000 iterations). The ARLEQUIN 3.0 software (Excoffier et al., 2005) was used to calculate observed $\left(H_{\mathrm{O}}\right)$ and expected $\left(H_{\mathrm{E}}\right)$ heterozygosities. All tests were corrected for multiple comparisons by Bonferroni's correction (Rice, 1989).

\section{RESULTS}

One hundred and ninety-five clones were sequenced, of which 114 contained microsatellite repeat tracts. This corresponded to an enrichment efficiency of $58.5 \%$. The most frequent microsatellite type was dinucleotide repeats $(75.2 \%)$, followed by tetranucleotide repeats $(12.6 \%)$ and trinucleotide repeats $(5.3 \%)$. Eighty-four primer pairs were designed. Sixty of 84 (Table 1) primer pairs successfully amplified PCR products. All 60 microsatellites were polymorphic (mean number of alleles $=4.12 \pm 1.48$, ranging from 2-9 per locus).

The $H_{\mathrm{E}}$ and $H_{\mathrm{O}}$ heterozygosities ranged from 0.10 to 0.88 (mean $0.47 \pm 0.20$ ) and from 0.07 to 0.87 (mean $0.40 \pm 0.22$ ), respectively (Table 1). No LD was detected between any two loci ( $\mathrm{P}>0.05$ after Bonferroni's correction). Sixteen loci (Table 1) showed significant deviation from HWE ( $\mathrm{P}<0.05$ after Bonferroni's correction).

\section{DISCUSSION}

In this study, we identified 60 polymorphic microsatellites. After characterization of the 60 microsatellites, we identified 44 polymorphic ones that showed HWE. These 44 microsatellite markers will be useful in characterizing wild populations of $H$. diversicolor, assisting the ongoing selective breeding programs of $H$. diversicolor and linkage mapping.

We noticed that 16 of 60 microsatellite loci $(26.7 \%)$ deviated significantly from HWE, which may be due to the presence of null alleles. This finding suggests a pervasive occurrence of null alleles at microsatellites of this species, which is consistent with the findings in other mollusks including pacific oyster (Hedgecock et al., 2004) and various abalone (Cruz et al., 
Microsatellite markers in Haliotis diversicolor

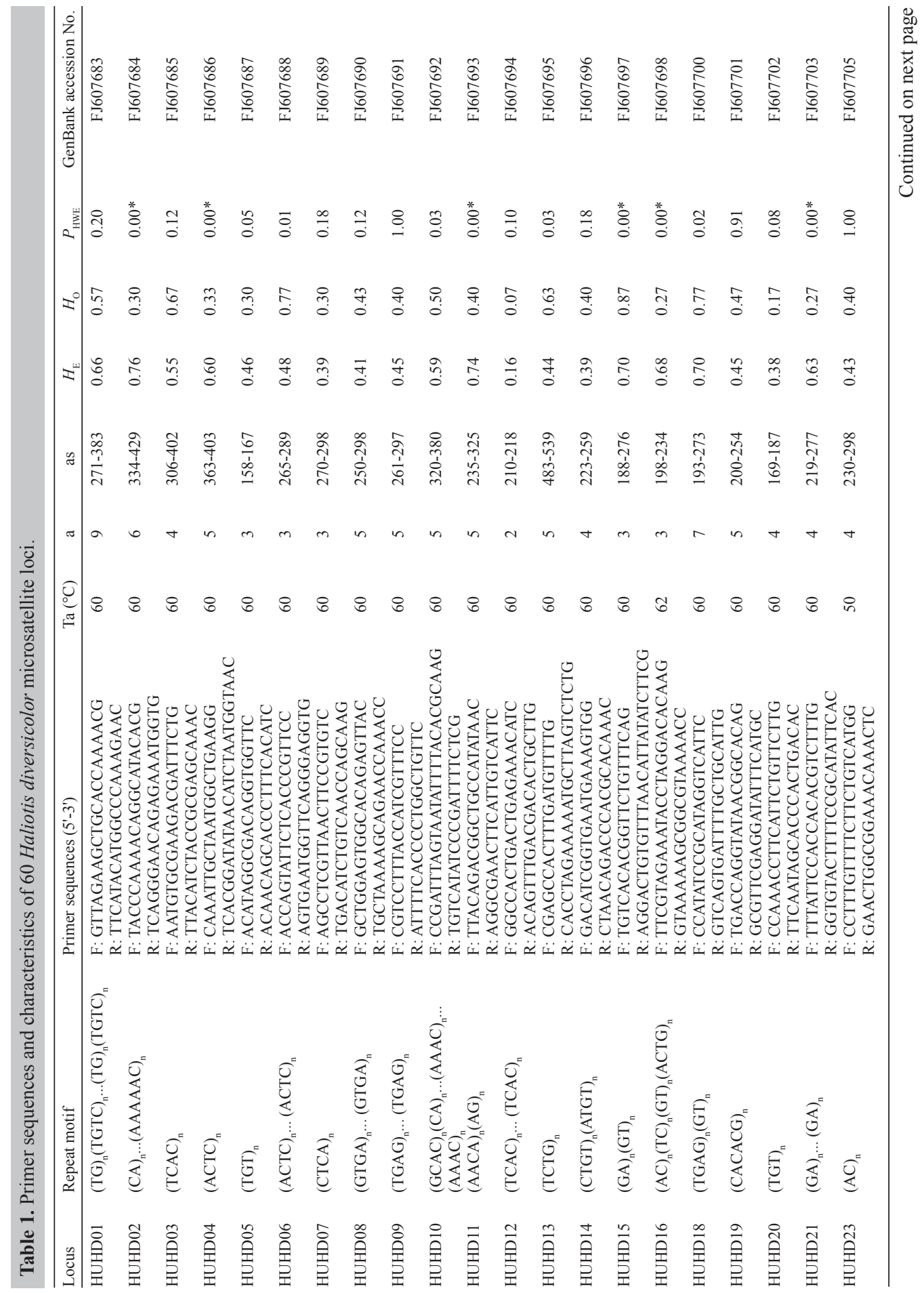

Genetics and Molecular Research 10 (2): 860-866 (2011) 
Y. Wang et al.

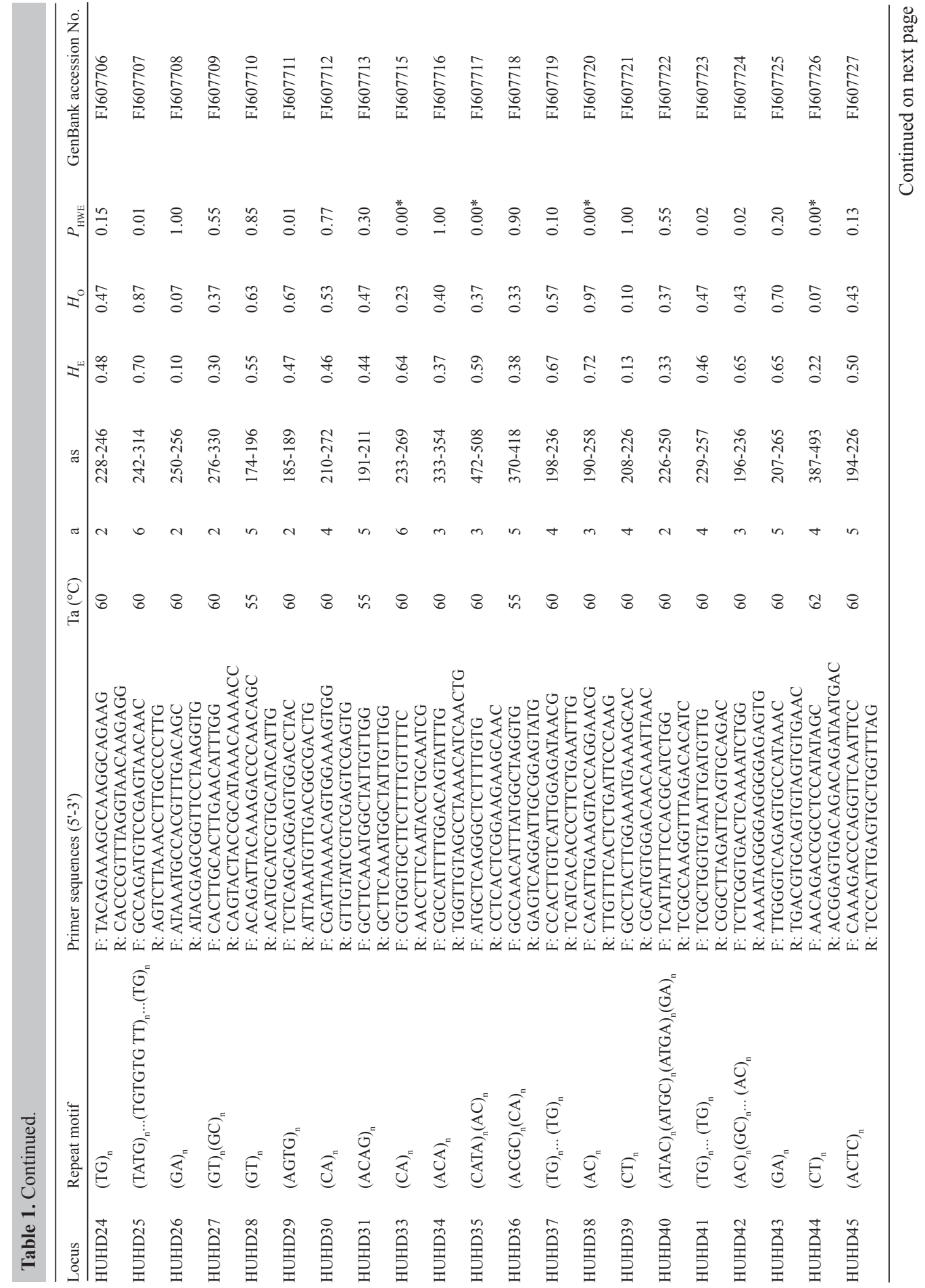




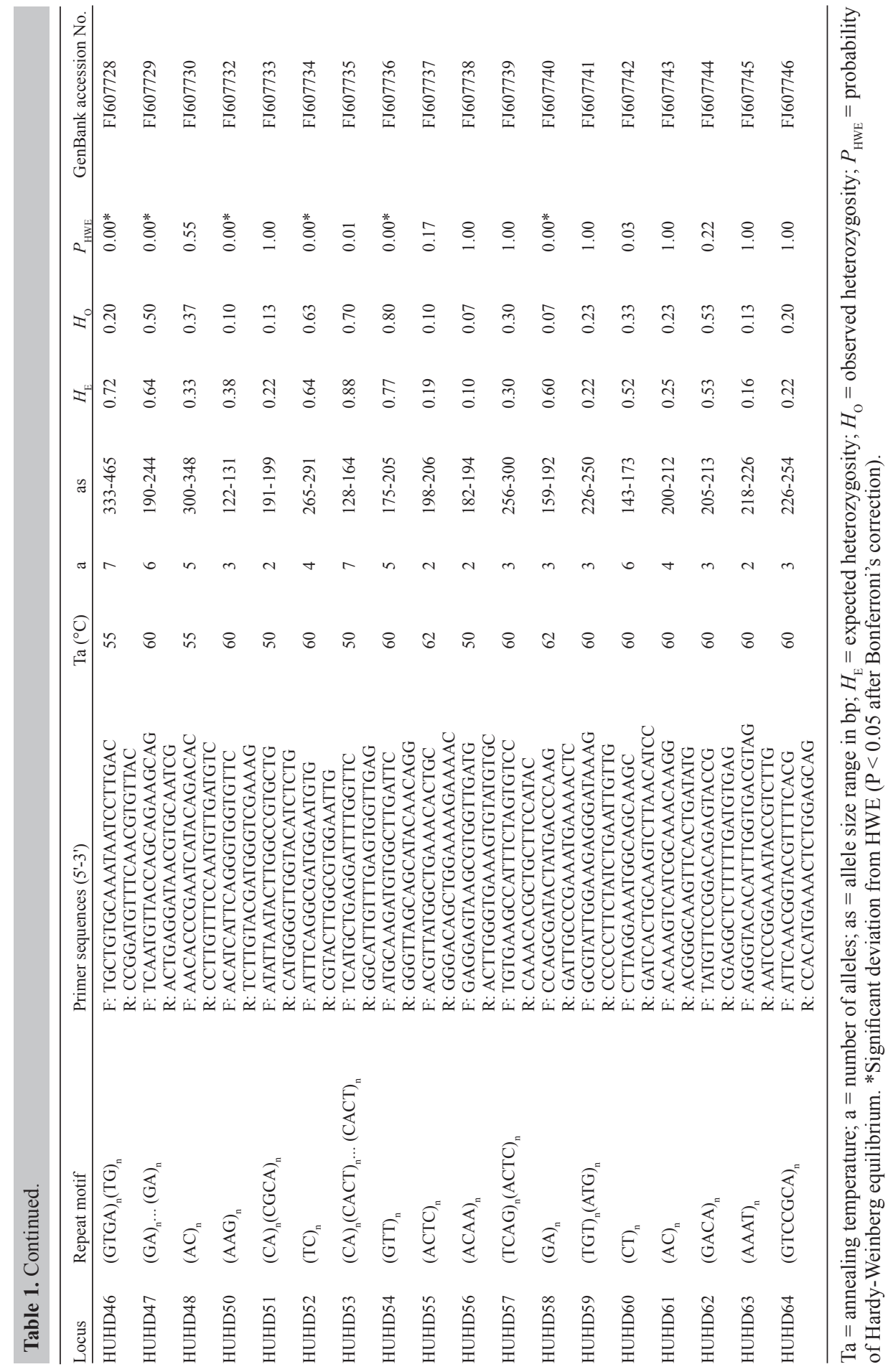


2005; Baranski et al., 2006; Ruhan et al., 2008). Null alleles tend to underestimate heterozygotes in natural populations and cause deviations from HWE. The occurrence of null alleles can pose a problem for the use of relevant microsatellite markers in population studies, although null alleles may not be a problem in mapping studies (Wang and Guo, 2007), especially for organisms with large family sizes (e.g., marine mollusks) (McGoldrick et al., 2000). Furthermore, the presence of null alleles can cause an overestimation of $F_{\mathrm{ST}}$ and some reduction in the percentage of correctly assigned individuals in parentage assignment (Carlsson, 2008). Therefore, caution must to be taken when these markers are used.

\section{ACKNOWLEDGMENTS}

Research supported by the National Natural Science Foundation of China (\#40866003 and \#31060354), the Special Program of the National Basic Research Program of China (\#2009CB126005), and Agricultural S\&T Commercialization Fund of Ministry of Science and Technology of China (\#376).

\section{REFERENCES}

Baranski M, Rourke M, Loughnan S, Austin C, et al. (2006). Isolation and characterization of 125 microsatellite DNA markers in the blacklip abalone, Haliotis rubra. Mol. Ecol. Notes 6: 740-746.

Carleton KL, Streelman JT, Lee BY, Garnhart N, et al. (2002). Rapid isolation of CA microsatellites from the tilapia genome. Anim. Genet. 33: 140-144.

Carlsson J (2008). Effects of microsatellite null alleles on assignment testing. J. Hered. 99: 616-623.

Cruz P, Ibarra AM, Fiore-Amaral G, Galindo-Sánchez CE, et al. (2005). Isolation of microsatellite loci in green abalone (Haliotis fulgens) and cross-species amplification in two other North American red (Haliotis rufescens) and pink (Haliotis corrugata) abalones. Mol. Ecol. Notes 5: 857-859.

Excoffier L, Laval G and Schneider S (2005). Arlequin (version 3.0): an integrated software package for population genetics data analysis. Evol. Bioinform. Online 1: 47-50.

Hedgecock D, Li G, Hubert S, Bucklin K, et al. (2004). Widespread null alleles and poor cross-species amplification of microsatellite DNA loci cloned from the Pacific oyster, Crassostrea gigas. J. Shellfish Res. 23: 379-385.

Ke C, Tian Y, Zhou S and Li H (2000). Preliminary studies on hybridization of three species of abalone. Mar. Sci. 24: 39-41.

McGoldrick DJ, Hedgecock D, English LJ, Baoprasertkul P, et al. (2000). The transmission of microsatellite alleles in Australian and North American stocks of the Pacific oyster (Crassostrea gigas): selection and null alleles. J. Shellfish Res. 19: 779-788.

Ren P, Wang Z, Yao C, Liu Y, et al. (2008). Development of 11 polymorphic microsatellite loci in the small abalone (Haliotis diversicolor Reeve). Mol. Ecol. Res. 8: 1390-1392.

Rice WR (1989). Analyzing tables of statistical tests. Evolution 43: 223-225.

Rouvay RW (2007). Abalone ranching: a review on genetic considerations. Aquacul. Res. 38: 1229-1241.

Ruhan S, Nicola RR, Nicol CVDB, Darrell LL, et al. (2008). Isolation and characterization of 63 microsatellite loci for the abalone, Haliotis midae. J. World Aquacult. Soc. 39: 429-435.

Schlotterer C (2004). The evolution of molecular markers-just a matter of fashion? Nat. Rev. Genet. 5: 63-69.

Shi Y, Wang Y, Qu Y, Ye H, et al. (2007). RAPD analysis on the first generation from inbreeding and crosses of wild and cultured abalone, Haliotis diversicolor Reeve. Mar. Fish. Res. 28: 47-53.

Wang Y and Guo X (2007). Development and characterization of EST-SSR markers in the eastern oyster Crassostrea virginica. Mar. Biotechnol. 9: 500-511.

Wang Y, Wang A and Guo X (2009). Development and characterization of 30 polymorphic microsatellite markers for the Atlantic surfclam, Spisula solidissima (Dillwyn, 1817). Mol. Ecol. Res. 9: 1264-1267.

Zhan X, Hu HY, Ke CH, Hu SN, et al. (2009). Isolation and characterization of eleven microsatellite loci in small abalone, Haliotis diversicolor Reeve. Conserv. Genet. 10: 1185-1187. 